\title{
CREER EN NADA. SOBRE LA CRISIS DEL CAPITAL
}

\section{BELIEVING IN NOTHING. ON THE CRISIS OF CAPITALISM}

\section{Leandro Drivet}

\author{
RESUMEN
}

Este artículo avanza en la comprensión de los sentidos político-culturales de la crisis capitalista global desde una perspectiva crítica, la cual atiende especialmente a la crítica cultural presente en la filosofía de Nietzsche. La decadencia de la religiosidad tradicional es menos analizada como efecto de la secularización ilustrada que como resultado del triunfo de la peculiar fe en el capital. Esta se piensa como consumación del nihilismo decadente, un creer en nada que revela la naturaleza impolítica del sistema de producción/destrucción contemporáneo.

PALABRAS CLAVE: TEORÍA SOCIAL * FILOSOFÍA * CAPITALISMO * RELIGIÓN * ÉTICA

\section{ABSTRACT}

This article moves forward into the comprehension of the political and cultural senses of the global crisis of capitalism from a critical point of view, specifically focused on the cultural criticism that pervades Nietzsche's philosophy. The decadence of traditional religiosity is assessed as a result of the success of the peculiar faith on capital rather than as an effect of illustrated secularization. This faith is thought to be a consummation of decadent nihilism, a "believing in nothing" that reveals the unpolitical nature of the contemporary system of production/destruction.

KEYWORDS: SOCIAL THEORY * PHILOSOPHY * CAPITALISM * RELIGION * ETHICS

Universidad Nacional de Entre Ríos (UNER) y Consejo Nacional de Investigaciones Científicas y Técnicas (CONICET), ambos de Argentina.

leandrodrivet@yahoo.com.ar 


\section{CREER QUE SE CREE}

"Es falso hasta el sinsentido ver en una 'fe', en la fe, por ejemplo, en la redención por Cristo, el signo distintivo del cristiano: sólo la práctica cristiana, una vida tal como la vivió el que murió en la cruz, es cristiana" (Nietzsche, 2008a: 77).

Corría el año 2006 y por enésima vez, las autoridades de la única (¿y última?) Monarquía Absoluta sobre la faz de la Tierra, analizaban con severidad la escasa concurrencia de fieles a las ceremonias sagradas. A una década de la percepción de Vattimo (1996) de un "renacimiento" de la fe, un matutino argentino (Diario La Nación), informaba ese domingo acerca de la preocupación del Vaticano por la reducción del número de católicos practicantes, especialmente en Europa:

Según las estadísticas, si bien entre 1978 y 2002 la población católica aumentó en el Viejo Continente (de 266 a 279 millones), la Iglesia católica sufrió una reducción del $18 \%$ en el número de sacerdotes, y la participación de los fieles a la misa dominical también decreció dramáticamente.

En la católica Irlanda, por ejemplo, mientras que en 1978 el 85\% de la población iba a la iglesia regularmente, hoy sólo lo hace un 44\%. En Italia, donde el 97\% de la población se considera católico, la participación cayó un 30\%, y en Francia, donde el $76 \%$ de la población se define católica, sólo el $12 \%$ dice que va a misa todos los domingos. Polonia es la excepción (Diario La Nación, 4/6/2006).

Hacia 2012, la Santa Sede sabe que en Suecia, el porcentaje de la presencia al culto dominical es de 1,5\%, del 3\% en Dinamarca y así, ínfimo, en todo el territorio de Europa. El problema que identifica la Iglesia es el debilitamiento del apego a las prácticas propias de una fe, no en cambio la disminución del número de creyentes, que habrían incrementado su número en Europa en un $4,5 \%$ en casi un cuarto de siglo. Como resulta evidente, la preocupación institucional de la Iglesia Católica va más allá de que ese dudoso aumento en los autoproclamados partidarios de la fe, represente un porcentaje inferior al del crecimiento vegetativo de la población.

Michel Pechêux (citado en Zizek, 2005: 158) expresa de modo sintético una idea que podría orientar la inteligencia del fenómeno: "las ideologías no están hechas de ideas sino de prácticas". La actitud de alarma ante los datos expuestos podría ser un signo de comprensión de esta sentencia. En su primer libro sobre la ideología, el esloveno Slavoj Zizek (2000) recupera a Blas Pascal para tratar de iluminar la estructura universal de la ideología, a través de la explicación del filósofo cristiano sobre la fe religiosa. Pascal observaba que para alcanzar la verdadera fe y librarse de la duda, había que abandonar el camino de la argumentación racional, de la explicación conceptual, para someterse al ritual, repitiendo los gestos sin sentido, las frases, las oraciones: actuando "como si" creyéramos que la creencia llegaría sola. Según este esquema, uno no reza porque es creyente, puesto que todo comienza al revés (cf. Zizek, 2000: 68-69). La fórmula de la fe expresaría más o menos lo siguiente: "arrodíllate, eleva plegarias, repite tales o cuales contenidos, pide perdón, agacha la cabeza, háblale a un Ser invisible, trátalo como a un superior, etc., y finalmente creerás". Esta sería la génesis de la religiosidad.

No es que el contenido de la creencia esté condicionado por la conducta, sino que habría, afirma Zizek (2000: 69), un status paradójico de una creencia antes de la creencia: "si sigue una costumbre, el sujeto cree sin saberlo, de modo que la conversión final es simplemente un acto formal por el cual reconocemos aquello en lo que ya creemos". Es decir: "la costumbre externa es siempre un soporte material para el inconsciente del sujeto" (Zizek, 2000: 69). Este fenómeno puede ser mejor comprendido si se atiende a lo que ocurre con su inversión: interpretando la sentencia lacaniana del Seminario 11 que afirma que la fórmula del ateísmo no es "Dios ha muerto" sino "Dios es inconsciente", Zizek (2008: 100) sostiene que 
"El ateo moderno cree saber que Dios está muerto; lo que no sabe es que, inconscientemente, sigue creyendo en Dios".

La prolongación en las múltiples neurosis cotidianas de la religiosidad tradicional se burla de las refinadas racionalizaciones conscientes que creen haber refutado la idea de Dios: la desclericalización no debería confundirse con la pérdida de religiosidad. De aquí que el tratamiento psicoanalítico no consista tanto en convencer al paciente de la verdad inconsciente de sus síntomas, sino en llevar al inconsciente mismo a asumir esta verdad. Pues bien, así como hay creyentes que no saben que lo son ("ateísmo ingenuo"), hay una metamorfosis no percibida de la fe tradicional en una especie de, si se me permite la tautología, "credulidad ingenua".

Entonces, si el problema es la disminución del número de católicos practicantes: ¿es que habría católicos no practicantes? ¿Qué flexible compromiso motiva a tantos individuos que no asisten al culto ni respetan otras tantas prescripciones "sagradas" a responder afirmativamente a una encuesta que lo interroga sobre su condición de religioso y de católico? ¿Miedo, hipocresía, ironía, ignorancia? Nietzsche (2008a) lo atribuía a la falta de sinceridad. Lo que lo hacía "estallar" era que a diferencia de otras épocas, la suya (que en este sentido también es la nuestra), "estaba enterada". "Lo que en otro tiempo no era más que algo enfermo se ha convertido hoy en algo indecente, es indecente ser hoy cristiano" (2008a: 75). Nosotros sabemos que en un teólogo hay mentira (a sí mismo, a los demás). Todo el mundo sabe que la religión es un instrumento de dominación " $y$, sin embargo - se enfurece Nietzsche-, todo sigue igual que antes" (2008a: 76). Aproximadamente, un siglo más tarde, Peter Sloterdijk (2007) desarrollaría un voluminoso y erudito libro centrado en un problema similar, el de la falsa conciencia ilustrada. Según las estadísticas, la religión mayoritaria entre nosotros es la de decir que se es católico. En otras palabras: la disminución de católicos practicantes equivale a la disminución de católicos.

A la luz de la historia de la Iglesia Católica en América Latina, nada impide pensar que estamos presenciando una venganza -en alguna medida, inconsciente - de los fieles traicionados por la jerarquía eclesiástica, cómplice ideológico de un sistema político desentendido de la "cuestión social". En territorio costarricense, el cual no constituye una excepción continental, las altas esferas católicas no atendieron durante la segunda mitad del siglo $\mathrm{XX}$, a la sensibilidad de las demandas de mayor compromiso hacia los problemas socio-políticos que afectan a las grandes mayorías. Dichos reclamos, muchas veces provenientes del ala cristiana de la "opción por los pobres", no se limitaban a rumores esporádicos, tuvieron mártires y desde la década de 1970 al menos, alcanzaron estatuto de cientificidad (Rodríguez, 1977 y Vargas, 1990). La "despreocupación" de la Iglesia por las cuestiones sociales, interpretada correctamente en los estudios citados como una posición política encubierta tras el manto de la "apoliticidad", quizá sea una de las causas de largo plazo de la "despreocupación" de aquellas mayorías por la "cuestión de la iglesia".

El asunto tiene algo de implosión. La Iglesia Católica cambia o muere: esta es la conclusión de Gianni Vattimo (Vattimo y Caputo, 2010), filósofo italiano que se define en su autobiografía (Vattimo, 2009: 11) como "cato-comunista", católico y comunista. Con el propósito de salvar a la Iglesia de ella misma, aconseja al Papa que hable sobre las Escrituras y que guarde un prudente silencio sobre temas como la familia y la educación sexual. Como filósofo y como creyente, Vattimo se refiere al fenómeno de la degradación de la fe cristiana en la sociedad occidental altamente diferenciada y espectacularizada, y se alarma frente a las formas primitivas de la religión televisiva que contrastan con la devoción, en retroceso:

Hay un falso universalismo promovido por los medios, que es muy contradictorio. La gente está más interesada en el espectáculo religioso que en su compromiso religioso. Uno de mis ejemplos favoritos es la celebración por parte de la iglesia católica romana del año del Jubileo en 2000. Mucha gente joven vino a Roma a escuchar al Papa. Muchos 
interpretaron este hecho como un ejemplo del auge de la religiosidad entre la juventud de hoy. Pero después de que se fuesen, cuando llegó el momento de limpiar el área donde los jóvenes habían pasado la noche, se encontraron trescientos mil condones (Vattimo y Caputo, 2010: 145-146).

El ejemplo es lo suficientemente elocuente como para entender la preocupación de la Iglesia por la disminución de la especie de los así llamados "católicos practicantes": bajo la forma de la deserción o de la concurrencia masiva a un espectáculo exótico o extraordinario, tambalea la consistencia de un soporte simbólico que legitimó y garantizó la subordinación, la disposición a la obediencia y la reproducción incuestionada de un dogma. Si algo faltaba para volver evidente la desustancialización de la fe católica era el "fotomontaje" de la empresa Benetton, en el que se vio al papa actual besar en la boca al imán de la mezquita Al Azhar de El Cairo, Ahmed Mohamed al Tayeb. La imagen ha corrido un paso más el límite de la desacralización tradicional (es curioso que el dogma y el protocolo de la religión del Amor fueran profanados en nombre del Amor. La campaña publicitaria de Benetton se tituló "Unhate"). El ridículo en que fue puesto Benedicto XVI, sumado a los contraproducentes efectos del intento del Vaticano por censurar la imagen, demuestran la debilidad y el des-crédito de la Iglesia Romana. La propaganda es una postal que sintetiza que el cristianismo solo triunfa bajo la forma del capital. La religión del dogma es cada vez más un fósil que no es combatido por aplastamiento, esforzado al desalojo, sino licuado en la incontrolable masa circulante de ofertas, yuxtapuesto, inscripto nuevamente $y$ catalogado en el repertorio global de las mercancías: peculiar ecumenismo del capital. Toda esta furia desacralizadora no desemboca en el ateísmo, posición intelectual que, como ya he apuntado, bajo la figura del ateo vulgar o ingenuo, supone resolver otras y más complejas dificultades. Se volverá sobre la cuestión del destino de la fe (en general) más adelante.

Contentémonos aquí con la necropsia del catolicismo. Una investigación reciente realizada en la Argentina, muestra desnudo el núcleo del problema en lo que atañe a la burocracia política; es decir, a la columna vertebral del poder. Investigadores del Consejo Nacional de Investigaciones Científicas y Técnicas han revelado que si bien, el 60\% de los legisladores argentinos se declara católico, la mayoría está dispuesta a votar leyes democratizadoras rechazadas por la Iglesia (Carbajal, 2012). La influencia de las convicciones religiosas manifiestas en las decisiones parlamentarias, no parece ser la clave para anticipar el voto de los representantes del pueblo de la Nación. Sin embargo, esta falta de coherencia entre pareceres generales manifiestos y pensamientos/conductas específicos, también da algunas señales de tranquilidad a la Iglesia Católica: mientras que la mayoría legislativa piensa que el Estado no debe sostener económicamente a los cultos, la subvención estatal de los colegios religiosos recibe mayor aceptación.

La hipótesis, por cierto nada nueva, sobre el hundimiento de la fe católica, permite pensar de otro modo incluso, algunos fenómenos que a simple vista parecerían indicar un reflorecimiento de la religión. El caso del ¿secuestro? de la Virgen del estadio del club Colón de la ciudad de Santa Fe, es uno de ellos. En septiembre de 2011, la representación en yeso de la Virgen de Guadalupe que ocupaba un sitio en una de las plateas del estadio de fútbol de Colón desde hacía una década, fue quitada del lugar sin previo aviso y sin ninguna explicación. Rápidamente corrieron rumores que hablaban de superstición: al parecer, las derrotas del equipo rojinegro se habían atribuido a la mala influencia de la Virgen, que pagó con el destierro. Según versiones extraoficiales, un brujo se habría encargado del exorcismo. No obstante, las deidades viven de muerte (Drivet, 2011) y lo narrado hasta aquí fue apenas el comienzo del culebrón santafesino protagonizado por una escultura. La comunidad católica hizo de inmediato su indignada aparición. Inquiridos, los jugadores del club, señalados como responsables del agravio, improvisaron una respuesta políticamente correcta que negaba las sospechas de (otro) paganismo que 
pendían sobre ellos y explicaron la ausencia de la imagen religiosa aduciendo que la misma se hallaba en manos del artista que la había esculpido, para ser restaurada. No faltaron en la ciudad ceremonias de "desagravio" ni discursos encendidos contra la iconoclasia, en defensa del símbolo derribado.

A primera vista, uno está inclinado a ver en esta saga grotesca el arraigo, la "vuelta de la fe" en un pueblo que mediante ritos $y$ contrarritos atestigua su inconmovible piedad. No obstante, otra hipótesis podría afirmar que estamos frente a un acontecimiento que ejemplifica y pone de relieve la crisis de la religión católica en una sociedad tradicionalmente ultracatólica (como prueban su nombre y su urbanización). En otras palabras, que todo lo ocurrido armoniza bien con el viejo truco de la compasión y de la intensificación de la culpa que le es concomitante: estrategia milenaria de probada eficacia a la hora de conquistar el corazón popular, cuyas sólidas seguridades de otrora se desvanecen en el aire en tiempos de matrimonio igualitario (uniones civiles homosexuales), despenalización del aborto, fertilización in vitro, educación sexual y salud sexual y reproductiva; en suma, en tiempos de laicización del Estado (en Costa Rica son contemporáneos los debates sobre la reforma del artículo 75 de la Constitución) y profunda crisis político-económica. Y de derrotas deportivas, claro.

Permeables al sentido común, los ciudadanos que albergaban un mínimo de simpatía por la religión, pero también aquellos que considera(ba)n con elástico sentido cívico a la estatua dañada parte del patrimonio público y aún quienes hubieran preferido preservarla por motivos artísticos e históricos, eran tentados a indignarse frente al "vandalismo" o la "superstición” (no cristiana) que había profanado un "símbolo" de la comunidad, arrastrándolo a comparaciones con espíritus "menos dignos" (i.e. menos espirituales, menos abstractos). Indignación que, habida cuenta de los antecedentes propios al interior de la Institución ofendida, mejor convendría denominar compasión. No pretendo abonar una interpretación conspirativa, que no puedo ni necesito probar.
Verdadero o no, que la presencia de un brujo y de un intento de exorcismo sea verosímil basta para advertir la devaluación de la fe cristiana y la presencia de un pensamiento mágico extraoficial "a la carta" (Angenot, 2011).

Sea como sea que haya sucedido, el hecho ya referido acarreó la multiplicación de la presencia mediática de los portavoces de la Iglesia, una, dos o quién sabe cuántas ceremonias de desagravio y de confirmación de la fe, el arrepentimiento público de los ídolos deportivos, ensayos de cien formas del padecer y compadecer: la puesta en funcionamiento de todo un sistema de invención de un sentir, de un recuerdo que en muchos casos es (el recuerdo) de ningún pasado; el recuerdo de cuán creyentes éramos, cuán pecadores, cuán corruptos. A juzgar por los resultados de este drama edificante, lo único que interesa es la dominación (cultural), que es lo que resulta reforzado. La jerarquía católica puede decir con razón (estratégica): "no hay mal que por bien no venga".

Esta religiosidad de los que creen que creen, se funda menos en la convicción que en el gesto en apariencia tolerante de no ofender o no escandalizar, $y$ hunde sus raíces en el rechazo telúrico que manifiesta la Iglesia Católica de los debates por un Estado laico (que no son ajenos a Costa Rica). Nada nuevo bajo el sol: la compulsión de pertenencia a la (supuesta) mayoría compacta es, al menos en una parte sustancial, el reverso del inveterado miedo a morir. No obstante, no convendría relativizar esta moralidad de la corrección pública ni confundirla con la pasividad. Estas ideologías fragmentarias, circunstanciales y fácilmente combinables con retazos de cualquier otra, suelen ser peligrosas por su carácter reactivo, escasamente mediado, superficial e irreflexivo (o especialmente irreflexivo).

El punto es que si ser ateo es muy difícil, creer en Dios tampoco es tan fácil. Creer que se cree, en cambio, creer en cualquier cosa de cualquier modo, sí. Esto recuerda nuevamente a Nietzsche (2007), quien advertía que debe haber algo de grandeza en un hombre, algo de esperanza $y$ de proyecto, para albergar e incluso soportar la idea de Dios. En este sentido, Cragnolini (1996) propone interpretar la sombra que 
acompaña a Zaratustra como el señalamiento del peligro (que acecha a los espíritus libres) de caer en los límites de una fe más estrecha. En términos nietzscheanos, el pedido de aparición de la estatua de la Virgen (la Virgen, suponemos, no podría desaparecer) y la celebración de los desagravios evocan menos al monoteísmo (incluso en su versión trinitaria) que a la "fiesta del asno" nietzscheana (adoración a un dios "tangible" y "evidente", a diferencia del invisible e inefable Dios-espíritu), pero actualizada esta, sin la risa deicida.

La decadencia de un dogma no se confunde con el ocaso de toda creencia rígida. Las masivas marchas en contra del matrimonio homosexual y de la despenalización del aborto, las inconmovibles defensas de un Estado confesional, de una educación "para el amor" que excluya la educación sexual no cristiana, son fenómenos que nos obligan a pensar en la vigencia de un dogma (inter)religioso descentralizado o en vías de descentralización, mantenido y reforzado por fuera de las instituciones $y / 0$ en instituciones intermedias, que mantiene núcleos ideológicos duros (aún) no disueltos que suscitan con facilidad la adhesión masiva y reportan sostén simbólico y beneficios económicos o políticos. Después de todo, aún cuando sea tan compatible con la religión, el patriarcado desborda a las religiones y la militancia que tiene como objetivo la perpetuación del displacer de otros (o el impedimento del placer), excede los dogmas particulares y se hunde en el enigmático corazón de la humanidad.

¿Se ha notado, pregunta Nietzsche (1992: 84), que el ocio (al cual no le es totalmente extraño el sentimiento aristocrático de que el trabajo deshonra) es necesario para una vida religiosa $y$ que "en consecuencia, la laboriosidad moderna, ruidosa, avara de su tiempo, orgullosa de sí, estúpidamente orgullosa, es algo que educa y prepara, más que todo lo demás, precisamente para la 'incredulidad'?". La intuición no era antojadiza: investigaciones relativamente recientes señalan que las condiciones laborales y sociales que sustentaron durante siete $\mathrm{u}$ ocho mil años, los sistemas $y$ modelos axiológicos y religiosos, cada vez existen menos, de modo que las religiones (cuya estructura imaginaria siempre tuvo un correlato con la estructura social y laboral) no tienen sistema laboral y técnico en el que apoyarse (Robles, 1996). La aceleración de los ritmos y la ampliación de los tiempos de producción (cuyos límites se desdibujan con los tiempos de la vida extralaboral), preparan para la indiferencia práctica. Esta se traduce, en opinión de Nietzsche, en circunspección y limpieza que rehúyen el contacto con personas y cosas religiosas. Interpretado en términos más amplios, el desmoronamiento de la fe religiosa podría ser apenas la parte más visible (más fácil de ver, más deseable) de un temblor más profundo y radical que amenaza arrojar el niño con el agua de la bañera.

\section{CREER EN (LA) NADA: LOS DESTINOS DE LA FE}

"En la grey no había amor al prójimo: sino sentido para el todo y respecto del prójimo, indiferencia.

¿Dicha indiferencia es algo bien elevado!"

(Nietzsche, 2008b: 835).

En su autobiografía, Sartre (2005: 85-86) narra el lento proceso de descristianización que había nacido en la alta burguesía volteriana y que luego de un siglo, alcanzaba todas las capas de la sociedad tocando a su propia familia:

Naturalmente que en nuestra casa todo el mundo creía: por discreción. Siete $\mathrm{u}$ ocho años después del Ministerio de Combes, la incredulidad declarada mantenía la violencia y la indecencia de la pasión; un ateo era un loco, un furioso a quien no se invitaba a comer, por temor a que 'hiciera una de las suyas', un fanático lleno de tabúes que se negaba el derecho a arrodillarse en las iglesias, de casar en ella a sus hijas y de llorar deliciosamente, que se imponía el probar la verdad de su doctrina por la pureza de sus costumbres, que se encarnizaba contra sí mismo y contra su felicidad hasta el punto de privarse del medio de morir consolado, un maniático de Dios, que veía Su ausencia por todas partes y que no podía abrir la boca sin pronunciar Su nombre; en 
una palabra, un señor con convicciones religiosas. El creyente no las tenía: las certidumbres cristianas habían tenido el tiempo suficiente de probarse en dos mil años, pertenecían a todos, se les pedía que brillasen en la mirada de un sacerdote, en la penumbra de una iglesia, y que alumbrasen a las almas, pero nadie necesitaba tomarlas en cuenta. Era el patrimonio común. La buena sociedad creía en Dios para no hablar de Él. ¡Qué tolerante parecía la religión! ¡Qué cómoda era! El cristiano podía faltar a misa y casar a sus hijos por la iglesia (...) no tenía ni que llevar una vida ejemplar ni morir desesperado; ni siquiera tenía que hacerse cremar. En nuestros medios, en mi familia, la fe no era más que un nombre de aparato para la dulce libertad francesa; me habían bautizado, como a tantos otros, para preservar mi independencia; si me hubiesen negado el bautizo habrían creído que violentaban mi alma; al ser católico inscrito, era libre, era normal. 'Más adelante — decíanhará lo que quiera'. Entonces se juzgaba que era mucho más difícil lograr la fe que perderla.

En una entrevista realizada en el Diario La Nación, el Presidente del Pontificio Consejo de la Cultura del Vaticano, cardenal Gianfranco Ravasi, afirmó que "con la secularización tendencialmente se es llevado a no considerar las grandes cuestiones, sino más bien a permanecer en un nivel superficial". En el marco del congreso interreligioso, organizado por él, en el cual se planteó el problema del ateísmo, distinguió dos modos del secularismo: uno agresivo, que combate explícitamente; otro, inconsistente, que opera por negación, por sustracción y que es más peligroso que el primero:

Yo personalmente — confiesa Ravasi- prefiero confrontarme con alguien que niega, afirma, declara, con motivos: esto es lo que hace falta hoy. Es decir, hay un ateísmo que no es el ateísmo de Marx, no es el ateísmo de Nietzsche, que era una visión de conjunto de la realidad, alternativa. Hay más bien un ateísmo de sustracción o indiferencia a nivel popular, no un ateísmo coherente, lógico. Diría que la Iglesia se enfrenta a esto (Diario La Nación, 25/10/2011).

¿Cuáles son las razones que explican este debilitamiento de la fe católica?, ¿es un éxito de la - para Marx - ya consumada "crítica de la religión”? y ¿si la crisis de la religión católica, religión que requiere (al menos en su versión autoconsciente) un grado de abstracción no menor, fuese apenas un fragmento de la más general crisis del Humanismo, se preguntan algunos? "Tanto mejor", responden otros, que identifican el Humanismo con la condición de posibilidad de Auschwitz. ¿Y si fuese parte del catabolismo del capital?

¿En qué creen los que no creen?, se interrogaban Umberto Eco y Carlo María Martini (1998) en un debate célebre cuyo título nos remite a la vigencia inconsciente de la religiosidad en los ateos vulgares. Al parecer fue Chesterton el que dijo que la muerte de Dios no trajo la incredulidad científica y reflexiva, sino la creencia en cualquier cosa. Habrá que ir más lejos, o quizá se deba decir: más abajo y más cerca. La satisfacción que nos suscita presenciar, el apagar histórico de una Institución que estrecha nuestros márgenes de libertad no alcanza para eclipsar que, por ejemplo, los Estados de clase en el mundo no cayeron ni caen por el avance de la crítica emancipatoria (con alguna excepción), sino por efecto de la crisis del capital y hasta en su nombre.

La religión, ha dicho un iconoclasta de modo célebre, es "la queja de la creatura en pena": ¿de qué se queja Ravasi, de qué se queja el Papa (en tanto instituciones)? Por un lado, el primero se lamenta de que con Dios parece haberse muerto el Demonio. No solo el ateo razonante sino hasta el ateo fanático, tan fácil de ridiculizar, parece haberse esfumado y con él, el soporte simbólico de una moral (de esclavos) que de modo eficaz distingue malos $y$ buenos, virtuosos y pecadores, siervos de la verdad $y$ desobedientes equivocados. Pero más importante es que Ravasi se queja de que lo ignoran. Se queja del "ninguneo" (que tan bien han sabido ejercer desde la institución que integra desde 
hace tanto tiempo). A decir verdad, ¿quién no preferiría como interlocutor a un teólogo como Ravasi, en lugar de los apóstoles del capital que creen tanto en el dinero como para impulsar en diferentes regiones de América Latina la "megaminería a cielo abierto" a costa de los glaciares, una de las reservas más grandes de agua dulce del planeta? La elección imaginaria del interlocutor se muestra falsa cuando aparecen en la agenda política temas como la despenalización del aborto o la separación entre Iglesia y Estado, $y$ los rivales mentados como diferentes, a saber, cristianos y capitalistas, muestran, mirados desde otra distancia y con las categorías que reparan en su mutua filiación (Benjamin, 2011 y Rozitchner, 2001), sus premisas comunes. En ambos sistemas de producción de subjetividad (que acaso sean momentos complementarios de uno solo) está vedado el diálogo $y$ puesto en riesgo, no solo una clase social ni la humanidad, sino la "biosfera" toda. El capitalismo también es, a su destructiva manera, trasmundista (¿un trasmundismo de clase?). Si esto fuera, como se supone, así la crisis religiosa podría ser pensada como un síntoma, la expresión neurótica de la crisis de confianza generalizada. Si toda religión es neurosis, no toda neurosis constituye religión.

No es esta una posición moralista que abogara por la re-ligazón en términos tradicionales. Se refiere a la crisis de confianza como una condición inmanente a la estructura del capitalismo que en nuestros días no hace sino estallar más ruidosamente. La religión, que había sobrevivido bajo la forma del capital, continuaría su proceso de degradación hasta acabar con las bases inmanentes de su prometida trascendencia. Del capitalismo puede decirse que al mismo tiempo que un "modo de producción" es un "modo de destrucción"; también, que no siendo una "cosa" ni una "cantidad" determinada de riqueza, el capital se ha definido desde Marx (1994) como una "relación social" que, en sintonía con la contradicción antes señalada, es la abolición de las relaciones sociales. Interesa entonces determinar la índole de esta "relación" en lo que tiene de específico para la praxis, es decir, en los vínculos de unos seres humanos con otros, y ya no tanto en las cualidades históricas que la distinguen de otros modos de relacionarnos con las cosas. La hipótesis que orienta nuestro horizonte teórico es que el capitalismo, heredero o metamorfosis del cristianismo, pone en suspenso la pretensión de diálogo de un modo radical y nombra un tipo de relación entre producción-destrucción y relación-no relación con un coeficiente negativo elevado.

Hay una homología axiológica estructural que habla de la filiación de la fe religiosa $y$ la fe en el dinero, cuya comprensión permitiría echar luz sobre el modo de alienación dominante de la actualidad. Con fines de definir la índole de la "relación social" capitalista, se intentará aproximar por la vía de la cultura política $y$ de la pregunta por su sentido, y ya no tanto por la vía de la crítica de la Economía Política, disciplina que no, sin cierta medida de justicia, monopolizó algún tiempo la administración (crítica) del "código genético" del capital. Después de todo, para escribir su "crítica" de la Economía Política, Marx (1994) bebió de fuentes ajenas a la Economía. Si se piensa en las crisis como momentos de revelación de la estructura del capital (crisis cíclicas) y no como excepciones a la regla, se podría postular que estamos atravesando un momento histórico donde quizá sea posible adquirir una particular nitidez acerca de la "naturaleza" del capital. En el ojo de la tormenta, se tendría la chance de abocarnos al pensamiento del sentido político-cultural de la crisis contemporánea por la vía de atrapar reflexivamente nuestras propias experiencias.

Se quisiera analizar la crisis desde una perspectiva que tenga su eje en la comunicación que ayude a volver transparente el doble filo de la extinción de la "fe". Si para ello, se partiera de la Teoría de la Acción Comunicativa, se debería establecer que es solo en los contextos de acción propiamente "comunicativa" donde los actos de habla pueden ser rechazados, tanto bajo el aspecto de la rectitud que el hablante reclama para su acción en relación con un determinado contexto normativo, bajo el aspecto de la veracidad que el hablante reclama para la mostración que hace de unas vivencias subjetivas a las que él tiene un acceso privilegiado y finalmente, 
bajo el aspecto de la "verdad" que con su emisión, el hablante reclama para un enunciado (Habermas, 1998). Cuando en cambio prima la "relación social" que es el capital (cuyo fin no es el entendimiento mutuo sino la maximización de la plusvalía), la acción comunicativa es parasitada en función de fines estratégicoinstrumentales, que a la larga amenazan con ahogar al huésped.

Esta perspectiva permite identificar, al modo de un negativo, algunos obstáculos efectivos de la pragmática del lenguaje, colonizada fundamentalmente por el interés crematístico. Cada pretensión de validez es violentada en particular (para probar se debería dedicar un estudio analítico exhaustivo). Se menciona aquí solo un aspecto de este proceso característico de la lógica impolítica del capital, quizá el más primario y profundo, sin duda el que aquí más interesa: bajo el señorío del incremento de la tasa de plusvalía, la "pretensión de veracidad", que según la teoría habermasiana, es una implicación universal del habla y de la acción comunicativa (Habermas, 1990 y 1998) y (desde una perspectiva emparentada) la "necesidad de reconocimiento" en sus diferentes dimensiones (Honneth, 1997) quedan en suspenso. Este proceso, que ya se verá, actualiza la iluminación nietzscheana sobre el concepto de "culpa" (Nietzsche, 2008a), atraviesa a todas las clases sociales. Sin embargo, se hace particularmente evidente si no se deja de atender a las desigualdades de clase. Es en las labilidades de la trama social donde esta se rompe primero $y$ donde la paradójica "lógica del absurdo" del capital revela, como supo Marx (1994), sus "resabios teológicos y sutilezas metafísicas": es el "pobre" (desposeído) el que está siempre en "deuda/ culpa" (Schuld); lo que se le exige (no sin violencia) es el cumplimiento mediante el pago. Los actos de habla son sucedáneos transitorios $y$ devaluados, meros prolegómenos del efectivo (cash) cumplimiento del deber de pagar. No hay nada que decir: en su desnudez, el capitalismo es mudo ( $y$ enmudecedor), como la violencia.

El desposeído vive en un intento interminable de expiación. La fe (crédito) que se le ha "regalado" (por Gracia de Dios), la fe que lo congració como apto para la fe, lo somete a una liturgia mensual. Lo que se le demanda es una acción consistente, viva o muerta y acumulada, por ejemplo, la realización de un sacrificio, que salde la duda abierta por él, deudor, como una herida. No es casual que la policía financiera llame "veraz" al sistema que monitorea, supervisa y etiqueta como confiables o no confiables a los individuos, invirtiendo de ese modo el principio oriundo del Derecho que presume a cada sujeto unschuldig: inocente/sin culpa/sin deuda.

La crisis vitalizante de la fe trascendente (fe religiosa) se prolonga como crisis mortificante de la fe inmanente (confianza práctica). La relación "social" capitalista subordina el amor del que depende la autoconfianza, el derecho que funda el autorrespeto $y$ la eticidad que sostiene la autoestima (Honneth, 1997), a la acumulación de la plusvalía. La filosofía de Hegel consideraba al amor el núcleo estructural de toda eticidad (Honneth, 1997). Atento a los devenires sexuados de la autoconciencia, también Freud (2004a: 98) reconoció en el amor, el corazón de la cultura: "en el [desarrollo] de la humanidad toda, al igual que en el del individuo, solamente el amor ha actuado como factor de cultura en el sentido de una vuelta del egoísmo en altruismo". La voluntad de maximizar la ganancia subvierte el fundante: Eros es sustituido por el "equivalente universal", ante cuyos ojos todos son iguales, pero iguales porque son "nada". ¿No será entonces el capital otro nombre de la indiferencia? Al punto de vista normativo habrá que complementarlo con la filosofía social, con el análisis de las pragmáticas específicas para demostrar que el "tipo ideal" de una "relación" bajo los términos del capitalismo, disuelve sistemáticamente la confianza, torna superflua la credibilidad porque convierte al otro en nadie.

El sistema de destrucción que se aloja en el mundo-huésped-de-la-vida (en nuestros cuerpos-huéspedes) institucionaliza la interacción que conduce al tipo de "vergüenza" al que Honneth (1997) atribuye la "crisis moral de la comunicación". En una crisis de este tipo, el individuo se siente oprimido por una sensación de falta del propio valor, porque sus compañeros de interacción han violado normas morales cuyo mantenimiento le había permitido 
valer como persona que desea conformarse a su yo-ideal. El fracaso de las expectativas no se neutraliza por la vía de la autoinculpación: es el caso de la "crisis moral de la comunicación", en la que se produce la frustración de expectativas normativas que el sujeto activo creyó poder depositar en la predisposición al respeto por parte del otro. En otras palabras: quienes debían responder por el individuo se ausentan propiciando que aquel sea violentado. El sujeto experimenta así, la dependencia constitutiva de la propia persona respecto al reconocimiento del otro, que desaparece. Este concepto bien podría tener el alcance de un diagnóstico epocal.

La "crisis moral de la comunicación" no se alimenta del moralismo convencional. Considerada "más allá del bien y del mal", permite postular que capitalismo significa entonces "necesariamente" des-confianza. El fenómeno de la hodierna crisis del capital muestra, si no se lo restringe a sus dimensiones económicas $-y$ no se lo amputa, por el contrario, de sus nexos con ellas-, una profunda crisis de la fe: no solo de la fe dogmática en un sistema religioso o doctrinario tradicional, sino de la fe en las relaciones intersubjetivas en las que se funda la política, el sentido de realidad y las identidades. ¿Y no es esta una de las peores caras del fenómeno moderno que Nietzsche llamó "nihilismo", el "nihilismo decadente"? $¿$ ¿No produce espanto la vigencia de la descripción nietzscheana (Nietzsche, 2007) del tiempo del "último hombre", aquel incapaz de anhelo, de amor, de creación, de nada grande, el pequeño-burgués devastado moral, intelectual y estéticamente que apenas puede creer en la Nada de su miserable felicidad?

Más allá de los méritos del Vaticano en el desplome de su autoridad (complicidad en genocidios, agresión sexual de menores, de poder, enriquecimiento con las manos sucias, etc.), $y$ del incesante andar de nuestro dios Logos -frente al cual, a la larga, estima Freud (2004b), nada puede oponerse-, lo que la "crisis de fe" puede estar queriendo decir, seguramente entre otras cosas, es que está en suspenso la verosimilitud de cualquier motivación de la acción que no sea la de la ganancia de dinero o poder. Esto podría incluir la duda acer- ca de la credibilidad de las promesas del dinero como mercancía: eventualmente, esta tendrá que abrirse camino ante el avance del desierto.

Por otro lado, la desmesura echa finalmente por la borda incluso, a los instintos autoconservativos. El "matar con la indiferencia" no necesita borrar las huellas de sus crímenes porque su crimen consiste en borrar: allí, donde no hay otro no puede haber asesinato. Si uno es deudor/culpable, un quebrado, un insolvente, no tendrá crédito, no tendrá confianza: será ninguneado, expulsado de la comunidad de los hombres. Al desposeído se le sustrae todo: incluso la posibilidad de prometer. ¿Y no es el ser humano, como afirma Nietzsche, el animal que hace promesas? Quizá pueda reinterpretarse desde esta perspectiva, focalizada en una fe desteologizada, el hecho de que Bloch (2004) haya pensado la crisis del mundo-capitalista como una crisis de la "esperanza". Sin posibilidad de explorar aquí la monumental crítica a la metafísica tradicional $y$ al existencialismo heideggeriano que es $E l$ principio esperanza, interesa destacar que allí se advierte que lo que se halla en cuestión es la posibilidad misma de "esperar activamente" (imaginar/construir un futuro) algo diferente de las previsiones "lógicas" del desenvolvimiento histórico regido por el capital.

Hay una escena actual que ilustra la actitud indolente, la indiferencia institucionalizada como "despotismo del capital" (Lambruschini, 2004). A comienzos del 2012 y según informaron numerosos diarios y portales de noticias, un hombre se descompuso en un banco de la Ciudad de México, comenzó a sufrir convulsiones y finalmente, murió ante la mirada de los otros clientes de la sucursal. Para no perder el sitio en la fila o para no abandonar sus asientos, ninguno de ellos se acercó a asistirlo. Luego de retirado el cuerpo del difunto, el gerente se negó a cerrar el Banco. He aquí condensada en una escena la lógica del capital. La agonía y la muerte de un hombre, solo en la multitud de la city. No hubo criminal en el proceso, aunque quizá asesinato. Solo testigos contemplativos de la fatalidad. ¿No es este, la hipérbole de la indiferencia en la matriz de la indiferencia, el corazón "cultural" del capitalismo? La indiferencia práctica 
precisamente no fue diferida: la necesidad de reconocimiento se manifiestó aquí y ahora, $y$ fue negada radicalmente: todo un sello de la Sociedad Anónima. Ni siquiera se trató de la anesthesia ante el dolor de los demás, lejano que suponemos, que quizá preferimos no conocer o elegimos pensar como eventual para proseguir nuestras vidas cada día. La muerte de Julián Tives León en ese banco de la Ciudad de México, nos enfrentó a la muerte del reconocimiento en vivo $y$ en directo, en las narices de nuestra conciencia, en las puertas mismas de nuestra percepción y no en ningún "más allá" que dependa para ser comprendido de encadenamientos racionales.

Antes que una regla, esta viñeta muestra un horizonte abismal posible (aunque imposible como horizonte). Una perspectiva unilateral tendería a subestimar la enorme potencialidad autoconservatoria $y / 0$ regenerativa de tejido social, que se habría desgarrado definitivamente, si el grado de reconocimiento actual no fuera igualmente elevado. Sin embargo, la escena del banco, que imaginada por un artista como alegoría del capital habría sido considerada inverosímil por perfecta, muestra el lazo filial que el capital ha tendido entre Oriente $y$ Occidente, asimismo nos enfrenta a algo peor que la indiferencia: su naturalización. El rechazo absoluto del reconocimiento (que exige en su estado puro el capital) conduce a la negación misma de la interacción. La indiferencia ataca las bases de la cultura, ya que el diálogo y la dimensión ética que este supone no están sujetos a la variable propensión sentimental de cada uno, sino que constituyen una condición fundadora de la individualidad.

Dicha condición tiene profundidades inconscientes que Habermas parece haber abandonado más allá de su aproximación temprana al psicoanálisis en la década del 60 . No obstante, su obra sitúa con insistencia la centralidad del diálogo y de la ética en los procesos de individuación. La disputa con el escepticismo ético organiza la argumentación habermasiana en Conciencia moral y acción comunicativa (1985), como una espiral en la que las posiciones de cada interlocutor, las del escéptico imaginado y las del propio Habermas, van radicalizándose. El carácter indispensable del Otro se vuelve patente hacia el final, cuando ante la posible huida del interlocutor, Habermas intenta probar que ni siquiera escapando de la argumentación es posible renunciar a la eticidad. Huyendo, el escéptico no podría negar ni siquiera de forma indirecta "que comparte cierta forma vital socio-cultural, que ha crecido en relaciones propias de la acción comunicativa y que en ellas reproduce su existencia" (Habermas, 1985: 124). La negación de la moralidad es posible, pero no en cambio la de la eticidad de las relaciones vitales en las que incluso, el escéptico participa a diario. Esta imposibilidad de escapar del lenguaje no es una mera suposición lógica: el abandono de la praxis comunicativa cotidiana es sinónimo de suicidio, de psicopatía o de psicosis. El lenguaje vulgar suele ser rústico en su lucidez y como ya se ha insinuado, ha comprendido el proceso que llama "matar con la indiferencia". Por frases como esta, el excomulgado Spinoza, condenado a un severo aislamiento, podría reprocharnos nuestra tendencia a desmentir que las metáforas son recuerdos no tan lejanos. Habermas conceptualiza:

Los particulares no tienen posibilidad de no participar durante largos períodos en los contextos de la acción orientada al entendimiento. Esta posibilidad supondría la retirada en el aislamiento monádico de la acción estratégica o en la esquizofrenia y el suicidio. A largo plazo, la posibilidad es destructora (1985: 127).

Lo dicho podría interpretarse como una réplica drástica a las implicancias "éticas" del capital, en tanto, demuestra el carácter destructivo de las premisas del modo de producción que garantiza la plusvalía, basadas en la indiferencia ante el reclamo de reconocimiento.

Se aproxima hasta aquí a una comprensión de la crisis epocal, en los términos de una crisis del reconocimiento fundante de cultura e identidad. No obstante, la crítica de la indiferencia estructural inmanente al capitalismo no es privativa de la teoría crítica en la forma de la Teoría de la acción comunicativa o de la Crítica del agravio moral (Honneth, 2009), de donde 
hemos querido extraerla por las pretensiones de universalidad de ambas.

Es notable que la relevancia del reconocimiento sea abordada desde teorías de la comunicación atentas a otro abordaje de la pragmática. Si se atiende al enfoque "sistémico" de Watzlawick, Helmick y Jackson (1981), este distingue tres posibilidades de respuesta del oyente ante la presentación que de sí mismo hace el hablante. La primera es la "confirmación" por parte del oyente de la definición que el hablante tiene de sí mismo. El efecto autoconfirmador es, de acuerdo a los estudios empíricos que sirven de sustento a la teoría de la comunicación humana de corte sistémica, el factor que más pesa en el desarrollo y la estabilidad mentales. En segundo lugar, el oyente podría "rechazar" la caracterización de que sí alberga una interacción con el hablante. No obstante $y$ por penoso que resultara, el rechazo supone al menos un reconocimiento limitado de lo que se rechaza $y$ por ende, no niega necesariamente la imagen que el hablante tiene de sí mismo. Más aún: el rechazo de propuestas transferenciales por parte de los pacientes psiquiátricos o psicológicos prueba que ciertas formas de rechazo pueden resultar constructivas. La trasposición de similares efectos reforzadores del rechazo sufrido por grupos sociales que reclaman por determinado reconocimiento de sus demandas políticas no es difícil de imaginar. Por último, el oyente podría recurrir a una tercera opción. Bajo el nombre de "desconfirmación" los autores citados llevan a concepto la posibilidad que tiene el oyente, no de rechazar el contenido de la pretensión de verdad que lleva el mensaje del hablante respecto a sí mismo, sino más bien de negar la realidad del hablante como fuente de tal definición de sí. Si el rechazo equivale a un desacuerdo, la desconfirmación afirma, sin articularlo verbalmente: "no existís". No sorprende entonces que esta posibilidad sea calificada como la más importante, tanto desde el punto de vista pragmático como desde el psicopatológico. La exposición sistemática a la desconfirmación conduce a sus víctimas a la "pérdida de la mismidad" o "alienación".

La experiencia clínica referida demuestra, en sintonía con la afirmación habermasiana, que el patrón familiar característico en familias de esquizofrénicos no incluye tanto a un hijo sometido a un descuido total o un trauma evidente, sino a un hijo cuya autenticidad se ha visto sometida a menudo involuntariamente, a una mutilación sutil pero persistente. Independientemente del significado que dé este a su experiencia vital, sus sentimientos no son tenidos en cuenta, sus actos son desconectados de sus motivos, intenciones y consecuencias, así como, la situación es despojada del significado que tiene para él. Así queda completamente confundido y alienado: la "labilidad del yo" que suele pensarse como causa, es desde esta teoría entendida como el resultado al que ha llevado la desconfirmación que sobre la identidad de un "yo" operaron sus otros constitutivos. Sin necesidad de amalgamar teorías de la comunicación con inocultables diferencias, lo que aquí interesa es que los efectos perniciosos de la indiferencia, a nivel de las distintas formas del reconocimiento $y$ de las pretensiones de validez, son corroboradas desde otra perspectiva pragmática de la comunicación.

Dado que el ninguneo o desconfirmación niega in toto el reconocimiento $y$ no solo la satisfacción de una pretensión específica de validez tematizada, su primacía a caballo del incremento de la plusvalía es una bomba de tiempo (time is money) en el aparato psíquico. La sentencia del tribunal de última apelación en el despotismo del dinero exclama: "si no tenés crédito, no existís". El dinero absorbe y cuantifica con el trabajo la identidad. ¿Cómo ex-sistir sin proyecto, sin promesa, sin esperanza? ¿Dónde "depositar" la confianza sin morir en el intento? El ninguneo, la matriz de la indiferencia de la que ahora se queja, incluso el Vaticano (que tanto hizo en su favor), desmonta la socialización, desmorona la subjetividad: si la cultura reúne las conquistas que nos separan, tanto desde el punto de vista técnico como desde el práctico, de la condena de la necesidad y sus automatismos, el capitalismo es por ende anticultural. El "sistema de producción y destrucción" que nos es coetáneo es paradójico, absurdo: se alimenta de un ansia trascendental más o menos consciente, a partir de la cual demuele toda confianza intersubjetiva. Supone un trasmundo en apariencia al alcance de la 
mano, a expensas del cual trabaja aniquilando el reconocimiento humano recíproco, parasitando hasta la muerte al "mundo de la vida".

La indiferencia como lógica inmanente, la desconfianza estructuralmente necesaria en el capitalismo, sistema que lleva al descrédito porque lo supone desde un comienzo, es la contracara del "creer en el capital", que no es otra cosa que la postergación indefinida del gasto, del placer, de la experiencia, de la existencia, de toda materialidad. La fe en el capital es en suma, otra forma del "sacrificio": otro nombre del "creer en la Nada", nihilismo decadente que destruye los presupuestos de toda fe. Se podría decir, parafraseando a Nietzsche (2008): "es que el hombre prefiere creer en la Nada a no creer...".

$\mathrm{Al}$ comienzo se ha referido, a los "sentidos de la crisis" actual del capital y hemos finalizado preguntándonos por la "crisis de los sentidos". La interrogación a la que hacemos lugar difiere de la preocupación por la crisis del sentido que motiva a Berger y Luckmann (1997) su conocido trabajo, puesto que para ellos la lógica del capital no parece tener la relevancia que aquí consideran insoslayable, a los efectos de comprender lo que parafraseando el concepto marcusiano de "represión excedente" podríamos llamar el "malentendido sobrante" de la comunicación humana (dejando por el momento de lado el "malentendido estructural"). Un abordaje como el que apenas introducimos debería ser capaz de atender a los destinos del sentido en sus diversas acepciones (en tanto significado, dirección $y$ sensibilidad) $y$ en sus posibles dimensiones (comunicativa, expresiva, constatativa $y$ normativa), sin arrancar este análisis de la matriz crítica del materialismo histórico. Se trata, creemos, de la crisis del sentido que la religión y el capitalismo llevaron a un estado crónico y agudo, crisis que condensa la pérdida de la experiencia (tanto de la capacidad de narrar, tan bien trabajada por Benjamin (1991), como de la confirmación de la validez de la experiencia sensible — anesthesia-), de la mundanidad $y$ de la política, $y$ las confunde con una condena inescindible de la cultura (confianza), en general.
A sabiendas de que cada acto de reconocimiento es un revés a la lógica pura del capital, un desafío que se abre para nosotros en plena crisis de escala planetaria, es el de reconstruir la "fe inmanente" que es la "comunicación" (praxis).

\section{BIBLIOGRAFÍA}

Angenot, M. "¿Hasta qué punto seguimos siendo muy píos?". Revista DEF-GHI 4 (4). 2012: 14-25.

Benjamin, W. El narrador. Madrid: Taurus, 1991.

Benjamin, W. "El capitalismo como religión". En: <http://catigaras.blogspot. com/2008/05/el-capitalismo-comoreligin-walter.html> [consultado el 3 de noviembre de 2011].

Berger, P. y Luckmann, T. Modernidad, pluralismo y crisis de sentido. La orientación del hombre moderno. Barcelona: Paidós, 1997.

Bloch, E. El principio esperanza. Madrid: Trotta, 2004.

Carbajal, M. "A Dios rogando, pero en la gente pensando". Diario Página 12. 14 de enero de 2012. En: <http://www.pagina12.com. ar/diario/elpais/1-185463-2012-01-14. html> [consultado el 15 de abril de 2012].

Cragnolini, M. B. "De la risa disolvente a la risa constructiva: una indagación nietzscheana”. Nietzsche actual $e$ inactual II. M. B. Cragnolini y G. Kaminsky (eds.). Buenos Aires: Oficina de Publicaciones del CBC, 1996: 99-122.

Drivet, L. "Nietzsche, Freud y la interminable agonía divina. Historia de un intento de homicidio". Revista DEF-GHI 4. Año 4, 2011: 74-85.

Eco, U. y Martini, C. M. ¿En qué creen los que no creen? Buenos Aires: Planeta, 1998.

Freud, S. (1921). Psicología de las masas y análisis del yo. Buenos Aires: Amorrortu, 2004a.

Freud, S. (1927). El porvenir de una ilusión. Buenos Aires: Amorrortu, 2004b.

Habermas, J. Conciencia moral y acción comunicativa. Barcelona: Península, 1985. 
Habermas, J. Teoría de la acción comunicativa. Tomo I. Madrid: Taurus, 1998.

Habermas, J. Pensamiento postmetafísico. México: Taurus, 1990.

Honneth, A. La lucha por el reconocimiento. Barcelona: Crítica, 1997.

Honneth, A. Crítica del agravio moral. Patologías de la sociedad contemporánea. Buenos Aires: Consejo Federal de Educación-CFE, 2009.

Lambruschini, G. El malestar actual y el despotismo del capital. MIMEO, 2004.

Marx, K. El Capital. Tomo I. México: Siglo XXI, 1994.

Nietzsche, F. Más allá del bien y del mal. Preludio de una filosofía del futuro. México: Alianza, 1992.

Nietzsche, F. Así habló Zaratustra. Madrid: Alianza, 2007.

Nietzsche, F. La genealogía de la moral. Buenos Aires: Alianza, 2008a.

Nietzsche, F. Fragmentos póstumos (18751882). Madrid: Tecnos, 2008b.

Piqué, E. "La caída en Europa es hoy el principal desafío para el Papa". Diario La Nación. 4 de junio de 2006. En: <http:// www.lanacion.com.ar/811642-la-caidaen-europa-es-hoy-el-principal-desafiopara-el-papa> [consultado el 30 de abril de 2012].

Piqué, E. "El Vaticano analiza el ateísmo como un fenómeno cultural". Diario La Nación. 25 de octubre de 2011. En: $<$ http://www.lanacion.com.ar/1417514el-vaticano-analiza-el-ateismo-como-unfenomeno-cultural $>$ [consultado el 30 de abril de 2012].

Robles Robles, J. A. "Religión y paradigmas. Modelo epistemológico y metodológico de Mariano Corbi”. Revista de Ciencias
Sociales de la Universidad de Costa Rica 72. 1996: 63-72.

Rodríguez, J. M. "Política y religión. La función política de la Iglesia Católica en Costa Rica”. Revista de Ciencias Sociales de la Universidad de Costa Rica 13 (13). 1977: 77-101.

Rozitchner, L. La Cosa y la Cruz. Cristianismo y Capitalismo (En torno a las confesiones de San Agustín). Buenos Aires: Losada, 2001.

Sartre, J.P. Las palabras. Buenos Aires: Losada, 2005.

Sloterdijk, P. Crítica de la razón cínica. Madrid: Siruela, 2007.

Vargas Arias, Claudio A. "La iglesia católica y el sistema político costarricense". Revista de Ciencias Sociales de la Universidad de Costa Rica 48. 1990: 79-87.

Vattimo, G. Creer que se cree. Buenos Aires: Paidós, 1996.

Vattimo, G. Ecce comu. Cómo se llega a ser lo que se era. Buenos Aires: Paidós, 2009.

Vattimo, G. y Caputo, J. Después de la muerte de Dios. Conversaciones sobre religión, política y cultura. Buenos Aires: Paidós, 2010.

Watzlawick, P.; Helmick, J. y Jackson, D. Teoría de la comunicación humana. Barcelona: Herder, 1981.

Zizek, S. El sublime objeto de la ideología. Buenos Aires: Siglo XXI, 2000.

Zizek, S. Ideología. Un mapa de la cuestión. 2da reimpresión. Buenos Aires: FCE, 2005.

Zizek, S. Cómo leer a Lacan. Buenos Aires: Paidós, 2008.

Fecha de ingreso: 23/05/2012 Fecha de aprobación: 31/08/2012 